\title{
Interaksi Simbolik sebagai Pembentukan Perencanaan Komunikasi Pemasaran (Studi Etnografi pada PT. Inti Ozzigeno Nara Solusi)
}

\author{
Bella Sisyadi, Muhammad Adi Pribadi \\ bellasisyadi@gmai.com,adip@fikom.untar.ac.id
}

Fakultas Ilmu Komunikasi Universitas Tarumanagara

\begin{abstract}
Integrated marketing communication is an activity to increase the sales, and to introduce a brand to people in an effective way using a consistent message for the appropriate target audience. PT. Inti Ozzigeno Nara Solusi is an advertising agency in Indonesia that implements integrated marketing communication to reach client's objective. PT. Inti Ozzigeno Nara Solusi has its own step of integrated marketing communication which is different compared to other advertising agencies. Symbolic interactionism takes an important role in creating the integrated marketing communication of PT. Inti Ozzigeno Nara Solusi. The research uses qualitative methodology with ethnography method. The data is obtained from participant observation, in depth interview with the team, and document analysis. The results concluded that PT. Inti Ozzigeno Nara Solusi has nine steps in the integrated marketing communication planning process that includes the following steps: OZIM, Brand and Competitor Analysis, Target Audience Research, to find 'Benang Merah' of client, Set Umbrella Communication, Set the integrated marketing communication strategy, Pitching with Client, Execute the Integrated Marketing Communication, and Monitoring. Symbolic interactions are found during the integrated marketing process such as rules, language of use, up to the company expectations.
\end{abstract}

Keywords: advertising, ethnography, integrated marketing communication, symbolic interactionism

\begin{abstract}
Abstrak
Kegiatan komunikasi pemasaran terpadu dilakukan untuk meningkatkan penjualan dan memperkenalkan sebuah merek kepada masyarakat dengan cara menetapkan cara terefektif dan pesan yang konsisten untuk target audience yang sesuai. PT. Inti Ozzigeno Nara Solusi adalah perusahaan periklanan di Indonesia yang menerapkan komunikasi pemasaran terpadu untuk memenuhi objektif klien. PT. Inti Ozzigeno Nara Solusi memiliki cara tersendiri dalam pembentukan perencanaan komunikasi pemasaran yang berbeda dengan perusahaan periklanan lainnya. Interaksi simbolik berperan penting dalam perencanaan komunikasi pemasaran PT. Inti Ozzigeno Nara Solusi. Penelitian ini menggunakan metodologi kualitatif dengan metode etnografi. Pengumpulan data dilakukan dengan observasi partisipan, wawancara mendalam dengan tim PT. Inti Ozzigeno Nara Solusi, dan analisis dokumen. Kesimpulan dari penelitian ini yaitu terdapat 9 tahapan perencanaan komunikasi pemasaran terpadu yang terdiri dari OZIM, Analisis Merek dan Kompetitor, Riset Target Audience, Menemukan 'Benang Merah' dengan klien, Menetapkan Umbrella Communication, Menetapkan Strategi Komunikasi Iklan, Pitching dengan Klien, Eksekusi Strategi Komunikasi Pemasaran Terpadu, dan Monitoring. Pada tahapan tersebut terjadi interaksi yang mengandung simbol-simbol seperti peraturan, penggunaan bahasa, hingga harapan para tim perusahaan.
\end{abstract}

Kata Kunci: etnografi, interaksi simbolik, komunikasi pemasaran terpadu, periklanan 


\section{Pendahuluan}

Iklan merupakan fenomena yang marak dijumpai pada era ini. Iklan berguna untuk memperkenalkan produk atau jasa yang dimiliki oleh sebuah perusahaan kepada khalayak luas terutama target audience dari perusahaan terkait selain itu, iklan juga merupakan suatu hal yang sangat penting bagi perusahaan-perusahaan dalam upaya mengembangkan pasar dan meningkatkan penjualan, namun tingginya tingkat kompetitor yang juga mengiklankan produknya membuat perusahaan harus cermat dalam menciptakan sebuah iklan yang efektif demi mencapai tujuan perusahaan dalam memasarkan produk atau jasa yang dimiliki.

Salah satu metode dalam beriklan adalah dengan menerapkan Integrated Marketing Communication atau Komunikasi Pemasaran Terpadu. PT. Inti Ozzigeno Nara Solusi merupakan salah satu perusahaan periklanan di kawasan Jakarta Utara yang menawarkan solusi periklanan yang tepat bagi para perusahaan untuk memasarkan produk atau jasanya. PT. Inti Ozzigeno Nara Solusi memiliki cara dan metode tersendiri dalam mempraktekkan Integrated Marketing Communication. Interaksi Simbolik selanjutnya akan menjadi fokus dalam penelitian etnografi komunikasi ini, dimana berdasarkan kegiatan pembentukan perencanaan komunikasi pemasaran oleh PT. Inti Ozzigeno Nara Solusi, maka perusahaan beserta anggota tim di dalamnya akan menciptakan interaksi dengan simbol-simbol baik verbal dan nonverbal tersendiri yang akan berperan dalam proses komunikasi pemasaran.

Rumusan masalah pada penelitian ini adalah bagaimana interaksi simbolik berperan dalam proses perencanaan komunikasi pemasaran di PT. Inti Ozzigeno Nara Solusi? Berdasarkan rumusan masalah tersebut, penelitian etnografi komunikasi ini bertujuan untuk mengetahui peran interaksi simbolik dalam proses perencanaan komunikasi pemasaran di PT. Inti Ozzigeno Nara Solusi.

Interaksi simbolik dan perencanaan komunikasi pemasaran merupakan kerangka pemikiran utama yang menjadi acuan di dalam penelitian ini. Konsep interaksi simbolik secara spesifik dengan konsep yang dipaparkan oleh Mead yaitu pikiran (mind), diri (self) dan masyarakat (society) dapat mengungkapkan interaksi yang terjadi di PT. Inti Ozzigeno Nara Solusi yang mengandung simbol verbal maupun non-verbal. Selanjutnya, konsep komunikasi pemasaran terpadu akan menjadi acuan untuk menjabarkan kegiatan pembentukan komunikasi pemasaran yang diterapkan pada PT. Inti Ozzigeno Nara Solusi.

Mead menjabarkan tiga konsep penting dalam teori interaksi simbolik yaitu pikiran (mind), diri (self) dan masyarakat (society). Ketiga konsep penting tersebut merupakan konsep yang tumpang tindih dan saling berkaitan satu dengan yang lain, hal ini merupakan gambaran dari teori interaksi simbolik secara global. Berikut ini merupakan penjelasan dari tiga konsep penting teori interaksi simbolik.

Pribadi, Suganda, Venus, dan Susanto (2018) mendefinisikan komunikasi pemasaran terpadu sebagai hasil penyatuan dari pemaknaan oleh setiap pemangku kepentingan agar menghasilkan satu tema komunikasi yang tepat dan konsisten untuk ditujukan kepada khalayak sasaran. Nickel (1984) mendefinisikan komunikasi pemasaran sebagai pertukaran pesan dua arah serta persuasi yang dapat menjadikan proses pemasaran menjadi lebih efisien dan efektif (Kusniadji, 2016). Selanjutnya, Percy (2008) mendefinisikan komunikasi pemasaran terpadu sebagai sebuah strategi komunikasi pemasaran terpadu yang merupakan suatu strategi untuk membangun hubungan yang saling menguntungkan serta kuat dengan stakeholder dan pelanggan. 
Bella Sisyadi, Muhammad Adi Pribadi: Interaksi Simbolik sebagai Pembentukan Perencanaan Komunikasi Pemasaran (Studi Etnografi pada PT. Inti Ozzigeno Nara Solusi)

Komunikasi pemasaran yang efisien dan efektif sebaiknya mendorong rencana tersebut.

Dalam memahami strategi komunikasi pemasaran terpadu sebaiknya didasarkan pada suatu proses perencanaan yang detil dan tepat sasaran. Strategi tersebut juga harus dikembangkan untuk mencapai tujuan baik tujuan perusahaan secara konsisten dan tujuan komunikasi untuk menemukan cara paling baik untuk penyampaian pesan. Percy menyebutkan terdapat 5 langkah dalam membuat perencanaan komunikasi pemasaran terpadu:

a Mengidentifikasi dan memilih target audience yang tepat;

b Menentukan bagaimana target audience membuat keputusan merek;

c Menyusun bagaimana mereka akan diposisikan dalam komunikasi pemasarannya dan pemilihan manfaat untuk mendukung posisi tersebut;

d Menetapkan communication objectives;

e Mengidentifikasi pilihan media-media yang cocok dengan communication objective untuk mencapai penyampaian dan pengelolaan pesan yang tepat.

\section{Metode Penelitian}

Penelitian ini menggunakan metodologi penelitian kualitatif dengan metode etnografi komunikasi. Metodologi penelitian kualitatif merupakan pendekatan penelitian yang mampu menggambarkan, menjelaskan, dan membangun hubungan dari kategori-kategori, dan data yang ditemukan (Kuswarno, 2008). Selanjutnya, metode etnografi komunikasi merupakan persepsi dan pengertian sistemik dari orang yang telah mempelajari suatu kebudayaan (Kuswarno, 2008). Peneliti menggunakan metode etnografi komunikasi untuk menggambarkan kebudayaan dengan segala interaksi yang terjadi di PT. Inti Ozzigeno Nara Solusi. Metode pengumpulan sampling pada penelitian ini menggunakan teknik Purposive Sampling. Purposive Sampling merupakan teknik penentuan sampel dengan pertimbangan tertentu (Sugiyono, 2016). Kriteria agar calon sampel sesuai dengan kebutuhan penelitian adalah pegawai tetap PT. Inti Ozzigeno Nara Solusi yang telah bekerja minimal 1 tahun.

Subjek penelitian pada penelitian ini yaitu tim PT. Inti Ozzigeno Nara Solusi. Penelitian ini merupakan penelitian etnografi komunikasi maka, peneliti akan mengkaji lebih dalam mengenai struktur bahasa dan perilaku komunikasi di dalam PT. Inti Ozzigeno Nara Solusi.

Objek atau yang disebut masyarakat tutur pada penelitian etnografi ini adalah interaksi simbolik dan pembentukan perencanaan komunikasi pemasaran di dalam PT. Inti Ozzigeno Nara Solusi yaitu interaksi antar anggota tim yang membentuk suatu situasi simbolik di dalam perusahaan dan komunikasi antara anggota dengan klien yang mencerminkan perencanaan komunikasi pemasaran terpadu dalam PT. Inti Ozzigeno Nara Solusi.

Teknik pengumpulan data primer dan sekunder dilakukan dengan observasi partisipan di kantor PT. Inti Ozzigeno Nara Solusi, wawancara mendalam dengan tim PT. Inti Ozzigeno Nara Solusi, dan Analisis dokumen perusahaan. Penelitian dimulai sejak tanggal 2 April 2019 hingga 11 November 2019.

Data-data hasil pengamatan akan diolah dengan teknik pengolahan dan analisis data yang dikemukakan oleh Creswell dalam Kuswarno, 2018 yaitu deskripsi, analisis, dan interpretasi. Deskripsi data disampaikan secara kronologis atau membangun cerita lengkap dengan alur, dan karakter-karakter yang hidup di dalamnya. Selanjutnya, pada 
tahap analisis, peneliti akan menjelaskan mengenai pola, dan regularitas perilaku dari objek penelitian yang diamati. Tahap terakhir yaitu interpretasi, peneliti melakukan penafsiran berdasarkan data yang diperoleh lalu menarik kesimpulan dari penelitian yang telah dilakukan.

\section{Hasil Temuan dan Diskusi}

PT. Inti Ozzigeno Nara Solusi sebagai perusahaan periklanan selalu berupaya menghasilkan iklan yang mampu memuaskan setiap brand yang menjadi klien. Dalam upayanya mencapai iklan yang efektif. Perancangan komunikasi pemasaran terpadu di PT. Inti Ozzigeno Nara Solusi dapat dijelaskan menjadi 9 tahap perencanaan komunikasi pemasaran terpadu yang terdiri dari OZIM, Analisis Merek dan Kompetitor, Riset Target Audience, Menemukan 'Benang Merah' dengan klien, Menetapkan Umbrella Communication, Menetapkan Strategi Komunikasi Iklan, Pitching dengan Klien, Eksekusi Strategi Komunikasi Pemasaran Terpadu, dan Monitoring.

\section{OZIM}

Setelah menerima klien brief, tim PT. Inti Ozzigeno Nara Solusi akan mengadakan OZIM (Ozzigeno Internal Meeting). Account Executive yang akan mengumpulkan para anggota tim dari salah satu Business Unit, OZIM akan dipimpin oleh Account Executive, Strategic Planner dan Designer atau Art Director yang telah menghadiri first meeting dengan klien. Dalam OZIM awal ini, tidak ada yang menjadi superior dalam menentukan pendapat, artinya semua anggota diperbolehkan untuk menyampaikan ide lalu, ide-ide akan dikumpulkan dan dirembukan bersama-sama.

Sebutan OZIM yang dimiliki oleh PT. Inti Ozzigeno Nara Solusi selaras dengan konsep Simbol Signifikan oleh Mead dalam Teori Interaksi Simbolik yaitu merupakan istilah khusus yang hanya diketahui oleh tim PT. Inti Ozzigeno Nara Solusi. Perilaku yang ditunjukan pada OZIM selaras dengan konsep Me yang dipaparkan oleh Mead bahwa anggota tim PT. Inti Ozzigeno Nara Solusi saling menurunkan ego nya masing-masing agar dapat menghasilkan iklan yang sesuai dengan strategi yang telah diterapkan guna mencapai keberhasilan.

\section{Analisis Merek dan Kompetitor}

Analisis Merek (Brand Analysis) adalah kegiatan melakukan riset mengenai merek dari calon klien untuk dianalisis secara mendalam mengenai nilai-nilai yang terkandung dalam merek tersebut. Analisis Kompetitor (Competitor Analysis) adalah kegiatan melakukan riset mengenai kompetitor yang ada disekitar merek klien untuk dianalisis secara mendalam mengenai karakter merek kompetitor hingga strategi komunikasi pemasaran apa saja yang telah dilaksanakan kompetitor. Tahap ini berguna untuk menentukan target market dan target audience yang cocok.

Sejalan dengan pemikiran Mead mengenai konsep Generalized Others dalam Teori Interaksi Simbolik yaitu aturan yang selalu dipegang oleh tim. Hal serupa ditemukan di pada Tim PT. Inti Ozzigeno Nara Solusi yang menjadikan analisa sebagai suatu hal yang harus dijalankan terlebih dahulu sebelum menentukan target market dan target audience yang cocok untuk klien. 
Bella Sisyadi, Muhammad Adi Pribadi: Interaksi Simbolik sebagai Pembentukan Perencanaan Komunikasi Pemasaran (Studi Etnografi pada PT. Inti Ozzigeno Nara Solusi)

\section{Riset Target Audience}

Riset Target Audience yaitu berkaitan dengan kebiasaan, kesukaan hingga sosial media yang biasa digunakan oleh target audience. Kegiatan ini akan dilakukan oleh Data Analyst. Konsep Generalized Others di dalam PT. Inti Ozzigeno Nara solusi seperti yang dipaparkan oleh Mead yaitu penempatan riset yang diakui bersama sebagai acuan. Perilaku yang ditunjukan oleh tim PT. Inti ozzigeno Nara Solusi ini, memperlihatkan bahwa PT. Inti Ozzigeno Nara Solusi selalu menjadikan riset dari divisi Data Analyst sebagai acuan dalam menemukan key message / key communication pada proses pembentukan perencanaan komunikasi pemasaran.

\section{Menemukan 'Benang Merah' dengan Klien}

Pada tahap ini, tim akan merembukan bersama hasil insight dari Data Analyst mengenai target audience dan diselaraskan dengan objektif klien. Alasan tim PT. Inti Ozzigeno Nara Solusi harus menemukan 'benang merah' tersebut karena tim menganggap bahwa iklan yang sukses merupakan iklan yang tidak hanya mampu memuaskan objektif klien namun juga iklan yang dapat diterima baik oleh masyarakat. Konsep Simbol Signifikan oleh Mead menjelaskan bahwa suatu komunikasi pemasaran yang berhasil adalah komunikasi pemasaran yang memiliki satu simbol yang sama dan diterima oleh klien dan masyarakat. Maka, penentuan key communication yang terjadi di PT. Inti Ozzigeno Nara Solusi dalam menemukan keselarasan saat menentukan key communication sangat sejalan dengan konsep Simbol Signifikan oleh Mead

\section{Menetapkan Umbrella Communication}

'Umbrella Communication' merupakan kata dari serapan Bahasa Inggris yang artinya adalah payung komunikasi. Alasan PT. Inti Ozzigeno Nara Solusi memilih kata 'Umbrella Communication' karena tim memandang key communication sebagai payung besar komunikasi yang menjadi naungan seluruh komunikasi pemasaran yang akan dieksekusi dalam satu periode iklan. Umbrella Communication inilah yang menjadikan inti pesan komunikasi pemasaran yang menjadi acuan agar komunikasi pemasaran tetap terarah dan konsisten.

Istilah 'Umbrella Communication' yang dimiliki oleh PT. Inti Ozzigeno Nara Solusi selaras dengan konsep Simbol Signifikan oleh Mead dalam Teori Interaksi Simbolik yaitu merupakan bahasa khusus yang telah diakui dan dipahami oleh tim PT. Inti Ozzigeno Nara Solusi.

\section{Menetapkan Strategi Komunikasi Iklan}

Berdasarkan Umbrella Communication yang telah ditetapkan bersama-sama, kemudian tim akan menentukan kegiatan untuk menyampaikan pesan komunikasi pemasaran melalui berbagai kegiatan seperti campaign, dan rancangan konten di berbagai sosial media yang sesuai dengan brand terkait. Dalam menetapkan strategi penyampaian komunikasi pemasaran, tim akan bekerja serempak menggunakan aplikasi google slide agar seluruh anggota tim dalam suatu Business Unit dapat melihat secara real time apa yang sedang dikerjakan satu dengan yang lain.

Selaras dengan paparan Mead mengenai konsep Generalized Others dalam Teori Interaksi Simbolik bahwa terdapat aturan bagi tim dalam bekerja. Teori tersebut menunjukkan bahwa penggunaan Google Slide berupaya agar tim bekerja dengan satu tujuan yang sama, sehingga pesan komunikasi konsisten dan iklan tercipta sesuai dengan objektif yang ada 


\section{Pitching dengan Klien}

Pitching adalah saat PT. Inti Ozzigeno Nara Solusi mempresentasikan deck proposal yang telah jadi dengan klien. Pitching akan dihadiri oleh keempat divisi yang seperti saat kegiatan first meeting dengan klien yaitu divisi Creative Director yang juga merupakan CEO perusahaan, Strategic Planner, Account Executive, Art Director atau Designer.

Sejalan dengan konsep Generalized Others yang dipaparkan oleh Mead dalam Teori Interaksi Simbolik bahwa seluruh anggota di dalam perusahaan dianggap sebagai satu kesatuan tim yang saling bersinergi tanpa sekedar memandang hierarki. Batasan lain yaitu untuk klien yaitu adanya perjanjian "all distribute to Ozzigeno" yang maksudnya semua presentasi pitching oleh Ozzigeno adalah milik Ozzigeno dan tidak boleh diperlihatkan kepada agency lain, jika melanggar maka pihak yang melanggar akan dikenakan sanksi hukum. Selaras dengan konsep Generalized Others yang dipaparkan oleh Mead dalam Teori Interaksi Simbolik yaitu peraturan yang dianut oleh anggota tim dalam berhubungan dengan klien.

\section{Eksekusi Strategi Komunikasi Pemasaran Terpadu}

Dalam proses eksekusi komunikasi pemasaran, tim akan mengerjakan pekerjaan sesuai dengan divisi masing-masing. Sebelum mengeksekusi komunikasi pemasaran tim PT. Inti Ozzigeno Nara Solusi akan mempresentasikannya dulu ke hadapan CEO yang juga berperan sebagai Creative Director.

Berkaitan dengan konsep Particular Others secara khusus yang dipaparkan oleh Mead bahwa terdapat sosok yang dianggap penting atau signifikan sebagai pemegang keputusan akhir.

\section{Monitoring}

Pada tahap ini tim akan melakukan monitoring secara intensif sejak iklan diluncurkan. Monitoring akan dilakukan setiap hari oleh divisi Sosial Media dan seminggu sekali oleh divisi Media beserta Data Analysis untuk memantau bagaimana performa penempatan iklan apakah sudah optimal atau belum berdasarkan brief dari klien.

Dalam kegiatan monitoring di PT. Inti Ozzigeno Nara Solusi, peneliti menemukan konsep Generalized Others pada cara Divisi Media yang menjadikan brief klien sebagai acuan dalam optimalisasi iklan.

\section{Konsep Interaksi Simbolik yang Terjadi Diluar Kegiatan Perencanaan Komunikasi Pemasaran di PT. Inti Ozzigeno Nara Solusi}

Selain berperan penting dalam pembentukan perencanaan komunikasi pemasaran, konsep interaksi simbolik juga ditemukan dalam keseharian tim PT. Inti Ozzigeno Nara solusi.

Konsep Generalized Others ditemukan pada:

- Visi: "Top 5 Digital Agency in the word"

- Misi: Menyediakan servis yang berkualitas dari sisi sosial media, konten, dan website, dan Membangun citra brand agar lebih baik untuk kedepannya

- Tujuan jangka pendek yaitu menjadi "Top 3 Digital Agency in Indonesia”

- Brand personality

- $\quad$ Tagline PT. Inti Ozzigeno Nara Solusi yaitu Happiness Brings Creativity

- Pembagian kerja: BU 1 dan BU 2 
Bella Sisyadi, Muhammad Adi Pribadi: Interaksi Simbolik sebagai Pembentukan Perencanaan Komunikasi Pemasaran (Studi Etnografi pada PT. Inti Ozzigeno Nara Solusi)

- Pemilihan Creative Director, Strategic Planner, Account Executive, Art Director atau Designer dalam menghadiri meeting dengan klien

Konsep efek Pygmalion ditemukan pada:

- Berbagai penghargaan yang berhasil diraih tersebut membuat tim

- Penghargaan tahunan seperti best of the best, terlucu, terajin, tersayang, dan sebagainya

Konsep Significant Symbol ditemukan pada:

- Bahasa Italia sebagai nama perusahaan

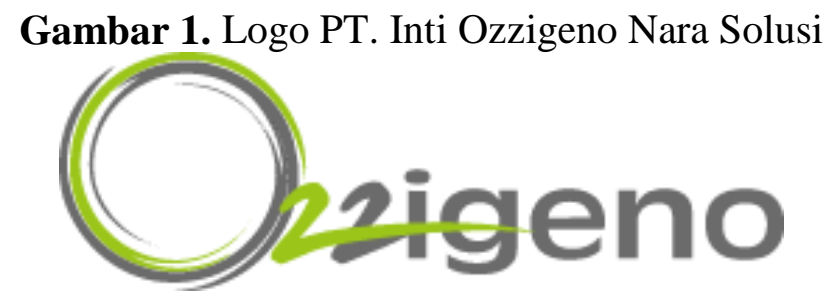

- Bahasa Inggris sebagai sebutan dalam struktur organisasi

Gambar 2. Struktur Organisasi PT. Inti Ozzigeno Nara Solusi

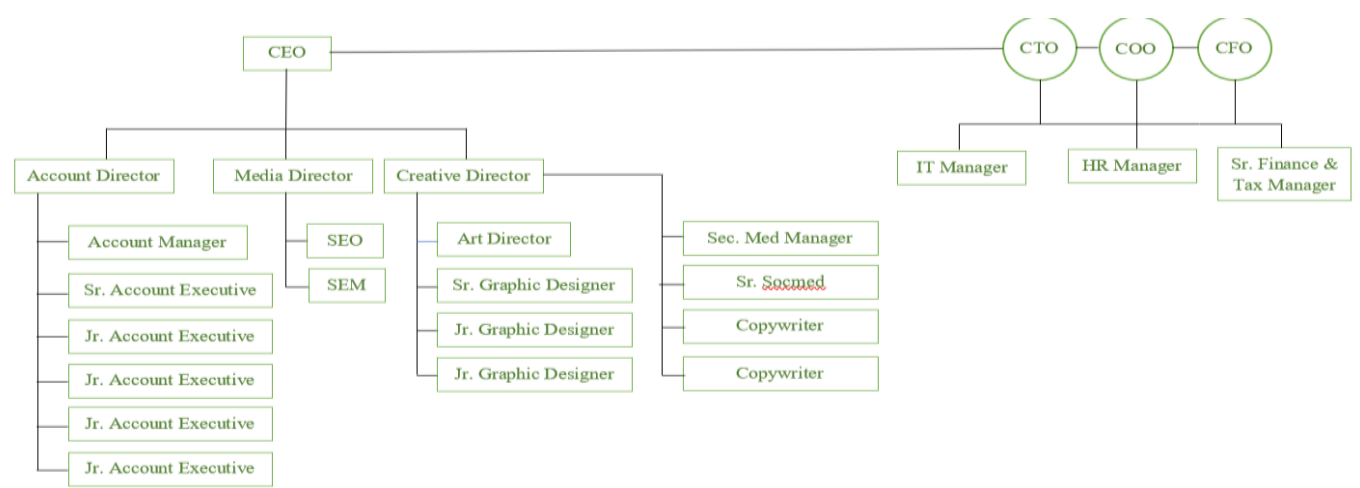

Sumber: Dokumen Perusahaan (2019)

- Kata 'OZIM'

- Strategi khusus yang membedakan PT. Inti Ozzigeno Nara Solusi dari perusahaan periklanan lainnya: 360 service, pelayanan berkualitas yang terjangkau, out of the box, dan menjunjung musyawarah dengan metode bekerja yang selalu dalam satu tim.

\section{Simpulan}

Berdasarkan hasil analisis data dan pembahasan yang telah dipaparkan di atas, maka kesimpulan yang ditarik oleh peneliti dalam penelitian ini adalah sebagai berikut:

1. Perencanaan Komunikasi Pemasaran Terpadu di PT. Inti Ozzigeno Nara Solusi dapat dijelaskan menjadi 9 tahapan perencanaan komunikasi pemasaran terpadu yang terdiri dari OZIM, Analisis Merek dan Kompetitor, Riset Target Audience, Menemukan 'Benang Merah' dengan klien, Menetapkan Umbrella Communication, Menetapkan Strategi Komunikasi Iklan, Pitching dengan Klien, Eksekusi Strategi Komunikasi Pemasaran Terpadu, dan Monitoring. 
2. Interaksi Simbolik yang terjadi pada PT. Inti Ozzigeno Nara Solusi berperan penting di dalam proses pembentukan perencanaan komunikasi pemasaran untuk memenuhi dan mencapai objektif klien.

3. Interaksi Simbolik yang terjadi pada PT. Inti Ozzigeno Nara Solusi berperan aktif dalam setiap penciptaan produksi iklan yang sesuai dengan harapan klien.

4. Interaksi Simbolik yang terjadi pada PT. Inti Ozzigeno Nara Solusi berperan penting dalam berbagai aspek kehidupan sehari-hari tim baik yang terjadi dalam hubungan internal dan interaksi dengan klien.

\section{Ucapan Terima Kasih}

Karya tulis ilmiah ini dapat terselesaikan karena bantuan dan dukungan dari banyak pihak. Oleh sebab itu, peneliti ingin menyampaikan rasa terima kasih yang sebesar-besarnya kepada Kriston Harjanto selaku CEO PT. Inti Ozzigeno Nara Solusi, dan seluruh informan.

\section{Daftar Pustaka}

Kotler Philip, Keller Kevin Lane (2012). Manajemen Pemasaran Terpadu edisi 12. Jakarta: Erlangga.

Kusniadji, Suherman. (2016). Strategi Komunikasi Pemasaran Dalam Kegiatan Pemasaran Produk Consumer Goods (Studi Kasus Pada PT Expand Berlian Mulia Di Semarang). Jurnal Komunikasi, 8 (1), 83-98. Juli, 2018. Terarsip di : https://journal.untar.ac.id/index.php/komunikasi/article/view/49/54

Kuswarno, Engkus. (2008). Etnografi Komunikasi:Suatu Pengantar dan Contoh Penelitiannya. Bandung: Widya Padjadjaran.

Ozzigeno. (n.d.). About Us. September 15, 2019.

http://www.ozzigeno.com/about

Percy, Larry. (2008). Strategic Integrated Marketing Communication: Theory and Practices. Burlington: Elsevier.

Pribadi, Muhammad Adi, Suganda, Venus \& Susanto, Eko Harry (2018). Dinamika Perusahaan Periklanan Indonesia: Studi Kasus Komunikasi dan Budaya Organisasi Dwi Sapta IMC dan Fortune Indonesia. Disertasi Universitas Padjadjaran. Bandung: Universitas Padjajaran.

Richard West, Lynn H.Turner. (2008). Pengantar Teori Komunikasi: Analisis dan Aplikasi (Buku 1) (Edisi 3). Jakarta: Salemba Humanika

Sugiyono. (2016). Memahami Penelitian Kualitatif. Bandung: Alfabeta. 